\title{
Crop Yield Prediction Techniques using Remote Sensing Data
}

\author{
Kuldeep Singh, Sunila, Sanjeev Kumar
}

\begin{abstract}
Crop yield prediction is an art of forecasting the yield of crop before harvesting. Prediction of crop yield will be very useful for the government to make food policies, market price, import and export policies and proper warehousing well in time. The socio-economical impact of crop loss due to any natural disaster i.e. flood, drought can be minimized and humanitarian food assistance can be planned. The paper present a literature survey of various stastical method, empirical models,artificial neural network and machine learning regression techniques which are used with the data provided by the satellites. Many models are developed and results calculated are compared with the benchmark models are also presented.
\end{abstract}

Keywords: Normalized Difference Vegetation Index (NDVI), Leaf Area Index (LAI), Support Vector Machine, Decision Tree, Neural Network.

\section{INTRODUCTION}

Agriculture is key section to contribute in the Indian economy and plays a vital role to ensure food security. India is one of the few countries in the world that uses land-based observations and space technology for generating regular updates to help the farmers which are beneficial in more crop production and provide inputs to achieve sustainable agriculture. These technologies contribute for taking informed decisions on food security issues and legitimate warehousing, timely availability of information on agriculture. To ensure food security, Government emphasizes on agriculture and launch scheme time to time. Some recently launched major schemes to enhance the productivity of the crops per drop more crop, crop insurance, Rashtriya Krishi Vikas Yojna. Wheat is the second most cultivated food crop in India after rice and feeds millions of Indians on a daily basis. India manages to produce about $8.7 \%$ of the total wheat production in the world. It is an especially important principal food in the northern and north western states of the country. Uttar Pradesh, Punjab, Haryana, and Madhya Pradesh are the prominent wheat producing states in the country. Haryana, located in the northern region of the country mostly known for its huge production as well as consumption of wheat. The state cultivate about 116.30 lakh net tons of wheat in an area of 25 lakh hectares all over the state.

Revised Manuscript Received on February 05, 2020.

* Correspondence Author

Kuldeep Singh, Department of CSE, GJUST, Hisar, India, kuldeep_cdlu@yahoo.co.in

Dr. Sunila, Department of CSE, GJUST, Hisar, India, sunilagodara@gmail.com

Dr. Sanjeev Kumar, Department of CSE, GJUST, Hisar, India,sanjukhambra@yahoo.co.in

(c) The Authors. Published by Blue Eyes Intelligence Engineering and Sciences Publication (BEIESP). This is an open access article under the CC BY-NC-ND license (http://creativecommons.org/licenses/by-nc-nd/4.0/)
Wheat crop yield can be forecasted by using many statistical methods like spatial sampling, meteorological model [32], crop growth model, remote sensing estimation and GIS [5,6]. In traditional wheat yield forecasting, manual surveys were conducted and require the exact information regarding the crop e.g., assessing their health, counting the plants, damage from pest and non-favourable environment etc. However, manual surveys are difficult and expensive. This task become easier with the enforcement of remote sensing techniques where the decision makers can imagine all the croplands with other related information and present state on single click. By using these technologies, the tasks like yield estimation and crop damage assessment can be accomplished within half or even in smaller time frame with minimum number of resources and elevated accuracy.

Satellite-based optical and radar images are widely used for monitoring agriculture. Integrated use of crop models with geospatial tools and exact observation network helps in forecasting of crops and drought monitoring and assessment.

Major advantages of crop yield forecasting before harvesting are:-

- Decisions of agricultural policy.

- Future crop planning and diversification.

- Drought declaration and contingency planning during shortage in food grain.

- $\quad$ Support in crop damage-assessment.

- Demand-based irrigation scheduling.

Remote sensing is technique of measuring the earth using sensors on satellites. Data collected by theses sensors in the form of images have dedicated capabilities for manipulation, analysis and visualization of images. Remote sensing imagery is incorporated within a Geographic Information System (GIS) which makes it feasible to gather data in unreachable and unsafe areas where it would be too unsafe to gather data with a team and equipments. These sensors are very high above the Earth, so they are very useful for collecting data of very wide area. Applications of remote sensing include water source management, monitoring the extent of deforestation and agricultural activities as well as monitoring the other activities happening on the earth.

Basically remote sensing is of two types a) Active sensing and b) passive sensing. Active sensing refers that the sensor of the overall system have its own source of light which generates signal which are to be projected on any surface and reflections are then collected back, for example to calculate the distance of a satellite from the surface a laser beam is fired and time it takes to reflect back is measured. Passive sensing refers that the sensors does not generate their own signal. It simply collects data that are already available. Remote sensing capture image and acquire information from a distance. 
Remote sensing is a powerful discipline because as a complete assortment of feasible wavelengths in the electromagnetic spectrum from small wavelengths (like Xrays) to long wavelengths (like radio waves) is available. Therefore, we can see beyond human vision. When sun emits light then each object reflects a combination of three colors i.e. red, green and blue. Similarly the satellites work when on board sensors emit light.

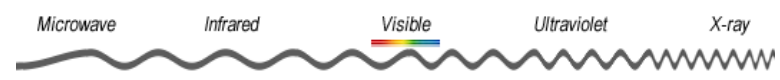

Fig.1 Electromagnetic Spectrum wavelength

Electromagnetic spectrum depicted in figure 1 show that human eyes respond in the visible spectrum from 390-700 nm. Near-infrared (NIR) light which is used for the vegetation indices is in the assortment of 700 to $1400 \mathrm{~nm}$. It is known that plants reproduce more green lights. Using indexes like NDVI (Normalized Difference Vegetation Index) we can classify healthy vegetation. In remote sensing each image have some specific bands to characterize that image with other image. Bands configuration used by remote sensing images is as follows:

- $\quad$ Coastal for Band 1

- $\quad$ Blue for Band 2

- $\quad$ Green for Band 3

- $\quad$ Yellow for Band 4

- $\quad$ Red for Band 5

- $\quad$ Red Edge for Band 6

- $\quad$ Near Infrared 1 for Band 7

- $\quad$ Near Infrared 2 for Band 8

\section{DEEP LEARNING TECHNIQUES}

Deep Learning allows computation having multiple processing layers to study data representation with multiple levels of abstraction. Output of each layer act as an input to the next layer. These methods outperform the up to date machine learning techniques in area of speech recognition, object recognition and detection , drug discovery, medical and remote sensing. Deep learning models are trained by using a large set of labelled data and with the neural network architectures having many layers to improve accuracy. Fig 2 shows deep learning and machine learning architecture which completely shows that high level of abstraction is provided in deep learning as compared to machine learning.

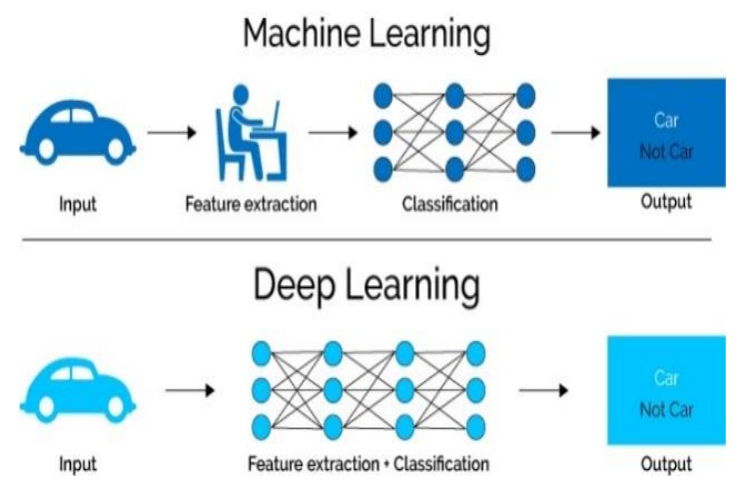

Fig.2 Machine learning v/s Deep Learning [33]

\section{Deep Learning Techniques:}

1. Convolutional Neural Network: Convolutional neural networks (CNN) is a type of neural networks which is used for image, time series and video analysis [29].After the successful learning of spatio-temporal features from videos, use of CNN for crop classification by using multi-temporal and multi-spatial remote sensing images is very emergent $[30,31]$. CNNrequires a minimum amount of pre-processing. The CNN architecture contains neurons in three extent i.e. width, height, depth shown by each layer. CNN architecture contains the following important features:

(a). Convolutional Layer: This layer consists of a set filters. The height and weight of these filters are lesser than those of the input value. Each filter is convolved with the input value to provide an activation function.

(b). Parameter Sharing: This feature facilitates the sharing of weights by all neurons in a particular feature map. This reduces the number of parameters to provide faster convergence and more efficient computation.

(c). Local Connectivity: In CNN, this feature provides a local connectivity pattern between neurons of adjacent layers. The neurons of each layer are only connected to the neighbouring neurons of adjacent layers. With this characteristics, CNN can deal voluminous input.

(d). Pooling Layer: Pooling layer is used to decrease the size of data which is obtained after adding Rectified Linear Unit (ReLU) and convolutional which avoid the major issue wuth neural network i.e. overfitting. Max-pooling is most famously used pooling technique.

2. Recurrent Neural Network: In RNN, connections between nodes form a directed graph[29]. The output from the previous step are fed as input to the current step. Internal memory is used to process the input sequences in this network. Earlier, in neural networks, inputs are not dependent on each other which leads to limitation for some tasks. In this network, output depends on the current timestamp as well as the previous timestamp. This type of network provides special abilities to use inputs in sequential manner. This also perform the same work for each element of the input sequence where the output depends on previous values. RNN is mostly used for stock market prediction and software reliability prediction. Fig 3 shows that RNN can recurrently apply the transformations to a series of known input vectors and generate a series of output vectors.

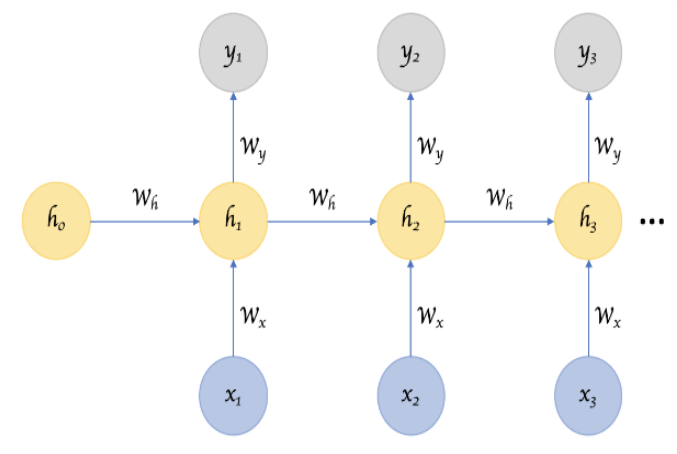

Fig.3 Recurrent Neural Network

Published By:

Retrieval Number: C6217029320/2020@BEIESP DOI: 10.35940/ijeat.C6217.029320

Journal Website: www.ijeat.org
Blue Eyes Intelligence Engineering

3684 \& Sciences Publication 
3. Deep Reinforcement Learning: Deep Reinforcement learning as shown in Fig 4carries an agent interrelating with an environment. The agent observes the situation of environment and take some actions which can change the situation of the environment. The objective of the agent is to be trained how to communicate with given environment to achieve objectives.

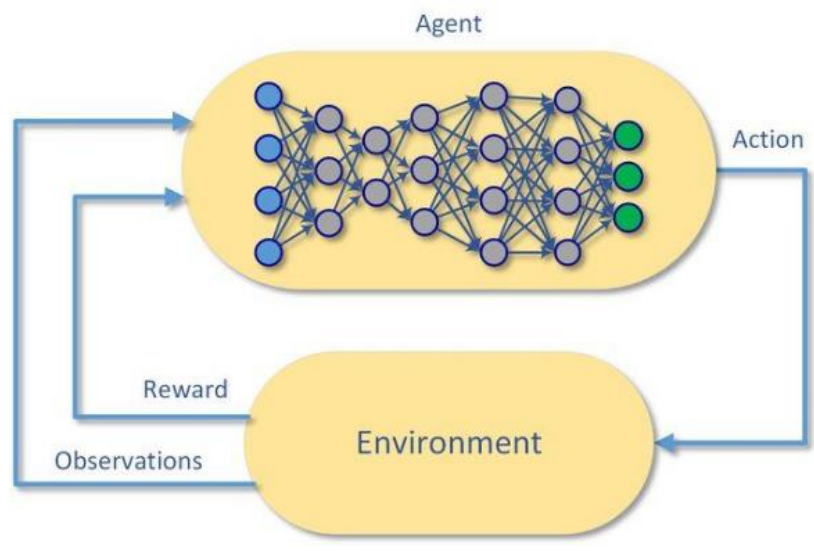

Fig.4 Deep Reinforcement Learning

This type of network predicts the expected value of future reward for each action, and then finds which action's can be predicted.

\section{III.METHODOLOGY FOR LITRATURE WORK}

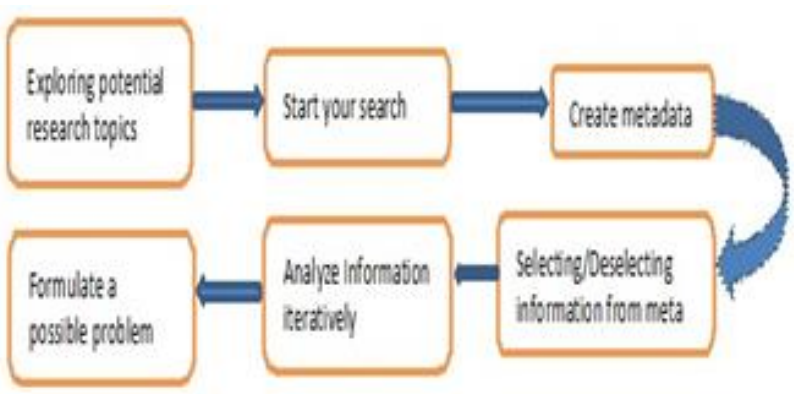

Fig. 5 Six step model for literature review

Fig 5 shows methodology for our paper. First step explore the related research field. After starting our research work we have to collect all the metadata/related information for our work. Then information related to particular field was selected. After analysis the results of different similar problems, the problem related to yield prediction was formulated.

\section{IV.RELATED WORK}

4.1.Aback-propagation neural network is proposed and conjugate gradient algorithm was used for training to predict the corn yield in Ottawa by using vegetation indices (VI) \& textural indices (TI) [1]. Four models based on BPN were trained with input VI, TI, VI \& TI and VI, TI, increase, slope and aspect respectively. Regression coefficient and RMS error were calculated as performance metrics which were compared with multiple linear regression method considered as benchmark and revealed that model 4 performed better than MLR method.

4.2.Rice-SRS (simulation remote sensing) model is developed to approximate the rice yield in China which accept input from remote sensing data [2]. Three kinds of normalized difference vegetation index (NDVI) inputs are given to the model i.e. (AVHRR LAC) NDVI Advanced very high promise radiometer local area coverage, (AVHRR GAC) NDVI superior very high resolution radiometer global area coverage and radiometric measurements NDVI. To accomplish the objective, leaf area index (LAI) is calculated individually for all inputs. Proposed model offers good results with AVHRR GAC input with less average error.

4.3.Advanced Wide Field Sensor (AWiFS) images were used with Monteith's model for evaluation of wheat yield in Haryana, India [3]. Remotely sensed approximation of photo unnaturally active radiation (fAPAR) and every day temperature were taken as input to estimate wheat yield. The major limitation of this model is that with the increase of heterogeneity of field crops the accuracy of the model decreases.

4.4. Support Vector Regression (SVR) method is used to predict the rice yield. The proposed model is divided in three steps [4]. First, SVR is applied to calculate the soil nitrogen weight. Second, SVR is appliedto calculate the rice stem weight. Third, SVR is applied to calculate the rice grain weight. The model performance is evaluated by mean absolute error (MAE) and mean absolute percentage error (MAPE) which is compared with their commercial model and shows that MAPE of proposed model is higher than that of commercial model but still in acceptable range i.e. $\pm 5 \%$. 4.5.RS-P-YEC (Remote Sensing - Photosynthesis - Yield Estimation for Crop) model was developed to estimate the winter wheat yield in North China [5]. The model used remote sensing data and meteorological data to gather the objective. Harvest index and net primary productivity was used to predict the yield of winter wheat crop. The results obtained by this model are compared with the observation of meteorological station where $\mathrm{R}^{2}$ reaches to 0.817 .

4.6. Relationship is developed between leaf area index (LAI) and yield to be predicted at each crop growth stage [6]. The study area is from North China. Savitzky-Golay filter (S-G filter) and Gaussian model is used to reduce influence of clouds and simulate daily crop LAI to get average at each crop stage respectively. A relationship between NDVI calculated from remote sensing imagery and LAI is also established to predict the wheat yield. The main disadvantage is that crop growth stage indicators are not discussed in the paper.

4.7. Different crop growth monitoring indicators used to monitor wheat crop at different stages through remote sensing in China [7] is discussed. NDVI studied so far has limitation in vegetation monitoring due to the existence of non-vegetation fraction and soil background. New vegetation indices such as soil-adjusted vegetation index (SAVI), modified soil-adjusted vegetation index (MSAVI), enhanced vegetation index (EVI) and perpendicular vegetation index (PVI) are discussed which plays an important role to achieve the accuracy in wheat crop yield prediction. The correlation coefficient calculated for all indicators and LAI reveals that SAVI with $\mathrm{L}=0.1$ outperforms in heading stage even when there are high crop cover.

Blue Eyes Intelligence Engineering 
4.8. The grades of a pilot study conducted by Ukraine Space Research Institute with the collaboration of Monitoring Agricultural Resources S (MARS) team to estimate the crop area out of a satellite imagery [28] are discussed. The study consisted of data set from five sensors i.e. MODIS, Landsat TM, AWiFS, LISS-III and RapidEye. Three classification algorithms are applied on the test data .

4.9. Aprogressive iteration method (PIA) was presented which was used to reduce the noise present in the dataset arriving from the moderate-resolution imaging Spectroradiometer (MODIS) [8].

4.10. provided an overview of the all crop yield forecasting methods by using manual surveys, crop simulation models and remote sensing data is presented [25]. It is mentioned that remote sensing techniques used for yield forecasting may not be suitable in developing countries because of their very small farm sizes and stratified agriculture system. However, this problem can be resolved with the availability of high spatial resolution images.

4.11. The corn yield in U.S.A. is estimated by using an estimation model of deep learning which is implemented with Convolutional Architecture for Fast Feature Embedding (Caffe) [26]. The network model of two inner product layer. The experiment is also carried out with single inner product layer and support vector machine. The highest accuracy s achieved by deep learning with two inner product layerwhen measured in terms of correlation coefficient and RMSE.

4.12.A flexible and extensible crop yield prediction framework is developed to predict the yield of crops from the remote sensing data [9]. In addition to NDVI, authors used temperature condition index (TCI) and vegetation condition index (VCI) as input for yield prediction. The framework is used to predict the yield of paddy, maize and greengram of Telangana state.

4.13.Three self-organizing map method, counter propagation artificial neural network (CP-ANN), XY-fused Networks (XY-Fs) and Supervised Kohone Networks (SKNs) is used to predict the wheat yield at Bedfordshire, U.K.[22]. They evaluated the wheat yield of 22 ha by using NDVI calculated from the satellite data and various physiochemical soil parameters e.g. $\mathrm{pH}, \mathrm{MC}, \mathrm{TN}, \mathrm{Mg}, \mathrm{Ca}$ etc. which are obtained from an online visible and nearinfrared spectroscopy sensor. The results obtained from the experiment reveals that SKN outperforms the other two models.

4.14. The efficient crop classification techniques is introduced which are used to identify a particular crop plot out of a parcel from multi temporal optical Landsat-8 and synthetic aperture radar (SAR) Sentinal-1 imagery [24]. A parcel based approach which involve a pixel-based classification map with the possibilities that a single parcel can contain many plots of different crops is used to carry out the study in Ukraine during 2013-2015 and it was concluded that we can rely on pixel based classification using the parcel boundaries for the best performance of crop yield prediction.

4.15. Data mining techniques are used to forecast the rice crop yield of 118 districts from nine south side states of India [10]. Four classifier namely J48, LADTree, IBk and
LWL are used to perform the task. Various performance metrics e.g. MAE, RMSE, RAE and RRSE are calculated and it is observed that J48 have highest accuracy and LWL performed with low accuracy.

4.16. Decision support systemis proposed for the yield prediction of rice crop in Maharashtra state of India [11]. To accomplish this task a GUI has been developed in JAVA by using Netbeans tool and Microsoft access as database. Various parameters used for inputs are precipitation, temperature and reference crop evapotranspiration. Output is classified in three categories i.e. low yield, moderate yield and high yield. Low yield range is from 0.15 to $0.60 \mathrm{t} / \mathrm{ha}$, moderate yield range is from 0.61 to 1.10 t/ha and high yield range is from 1.11 to $3.16 \mathrm{t} / \mathrm{ha}$.

4.17. Artificial neural network with multilayer perceptron technique is used to predict the rice crop yield in Maharashtra [12]. Dataset prepared from various input parameters like precipitation, temperature, evapotranspiration and area is processed through Waikato Environment for Knowledge Analysis (WEKA) tool for further processing. Specificity, sensitivity and accuracy is calculated from the dataset.

4.18.The first spiking neural network computational model is introduced to predict the wheat crop yield from the data obtained through MODIS in the Shandong region of China [13]. RMSE, RE, MAE and MBE were calculated from the NDVI sample space. The results are calculated with the WEKA software. The yield is predicted six week before actual harvesting with $95.64 \%$ accuracy and average error of $0.236 \mathrm{t} / \mathrm{ha}$.

4.19.Two machine learning algorithms, Boosted Regression Tree (BRT) and Support Vector Machine (SVM) were compared for prediction of wheat crop yield [14]. Three types of NDVI-related predictors derived from the low resolution imagery i.e. Single NDVI, Incremental NDVI were used for analysis. Initially both models were used to select the features having high impact in yield prediction and then these models were applied to the subset of particular features for yield forecasting. The results revealed that BRT performs better than SVM.

4.20. A multilevel deep learning approach is proposed for classification of land cover and different types of crops by using multi temporal multisource satellite images [21]. The architecture proposed uses both supervised and unsupervised neural networks for segmentation and classification of satellite imagery dataset respectively. The research was performed in Ukraine on the data received from Landsat-8 and Sentinal-1A scenes using multilayer perceptron and convolutional neural network. The architecture implemented with CNN outperforms the MLP.

4.21. An accurate and inexpensive method is introduced to predict crop yield using remote sensing data. The experiment was carried out in U.S. to predict the soybean crop yield [23]. A dimensionality reduction technique to train a convolutional neural network (CNN) and long-short term memory (LSTM) is introduced to accomplish the experiment. 
The RMSE and mean absolute percentage error (MAPE) were evaluated as performance metrics and it was observed that LSTM and CNN outperformed when compared with the baseline methods i.e. ridge regression and decision tree. Further LSTM and CNN performed much better when added with Gaussian Product and RMSE is reduced by $30 \%$ when compared with the ridge regression method. Results also reveals that MAPE is also decreased by $15 \%$ when compared with USDA prediction.

4.22. Two models are used for yield prediction of maize crop i.e. a) yield (Y) as a function of LAI and b) yield (Y) as a function of NDVI [15]. The data used in the study is obtained during the flowering stage of the crop. The LAI derived prediction model over estimated the yield by $14 \%$ whereas the NDVI derived prediction model attained $97 \%$ of accuracy.

4.23. The rice growth position and yield was predicted using multi-satellite data by using the image data of Landsat 7, 8 and Sentinel 2A [16]. The research was carried out in paddy field of northern part of Japan. Authors monitored the rice growth and estimated chlorophyll content in leaves of rice at brand rice production. The leaf chlorophyll content estimated from the satellite was converted from normalized difference vegetation index (NDVI) to soil plant analysis development (SPAD) value.

4.24. A model named Weather-based Prediction System for Rice Yield (WPSRY) is presentd for predicting rice yield in Bangladesh [17]. The model first predicts the weather parameters by applying neural network and then these

\section{RESULT ANALYSIS}

parameters along with current agricultural data are used as input for Support Vector Regression (SVR) method to predict the rice crop yield.

4.25. A crop simulation model is proposed to predict the rice crop yield in Tamilnadu, India [18]. The model uses various parameters e.g. soil, temperature, no of sunshine days, rainfall, plain land, fertilizer to perform the task. The target value is predicted based on mathematical and statistical functions and it is fundamentally correct compared to traditional mental method employed. The method proposed helps in predicting accurate value of yield.

4.26. Two algorithms i.e. Multiple Linear Regression (MLR) and K-Nearest Neighbor Regression (KNNR) are compared to determine which crop to be seeded to gain maximum yield per unit area [19].

4.27. A 3D CNN models was developed to learn spatiotemporal features from multispectral remote sensing images dataset for crop classification/prediction [27].

4.28. Advanced machine learning techniques i.e. boosted regression tree, random forest regression, support vector regression, and Gaussian process were used for yield prediction of silage maize by using time series images of Landsat 8 [20]. The NDVI standards of all fodder maize fields were collected and incorporated to produce a twodimensional dataset for every year to attain the task. The results shows that machine learning techniques perform better than conventional regression method as these methods have extra capability to covenant with high dimensional data of composite distribution.

Table 1 shows that different machine learning techniques are widely used for crop yield prediction. Each technique has its advantages and limitations. Analysis of these techniques showing their major findings is done in Table1.

Table-I: Complete analysis of various yield prediction techniques

\begin{tabular}{|l|l|l|l|}
\hline Sr. No. & Author Name & Methodology Used & Major Findings \\
\hline 1. & Charles Z. S. et al. (2000) & $\begin{array}{l}\text { Back propagation neural } \\
\text { network }\end{array}$ & $\begin{array}{l}\text { Four models are proposed and trained. } \\
\text { Fourth model performed better than } \\
\text { benchmark MLR model. }\end{array}$ \\
\hline 2. & $\begin{array}{l}\text { Huang Jinfeng et } \\
\text { al.(2001) }\end{array}$ & $\begin{array}{l}\text { Simulation Remote } \\
\text { Sensing Model (SRS } \\
\text { model) is proposed. }\end{array}$ & $\begin{array}{l}\text { Three kinds of input is given and LAI is } \\
\text { calculated. The model offers good result } \\
\text { with AVHRR GAC input. }\end{array}$ \\
\hline 3. & Patel et al. (2006) & Monteith's Model & $\begin{array}{l}\text { With heterogeneity of crops the accuracy } \\
\text { of model decreases. }\end{array}$ \\
\hline 4. & $\begin{array}{l}\text { Ratchaphum Jaikla et al. } \\
\text { (2008) }\end{array}$ & $\begin{array}{l}\text { Support Vector } \\
\text { Regression (SVR) } \\
\text { Method is proposed. }\end{array}$ & $\begin{array}{l}\text { MAPE and MAE are calculated and } \\
\text { compared with commercial model. MAPE } \\
\text { of proposed model is higher but still in } \\
\text { acceptable range. }\end{array}$ \\
\hline 5. & $\begin{array}{l}\text { Wang Peijuan et al. } \\
\text { (2009) }\end{array}$ & $\begin{array}{l}\text { Remote Sensing - } \\
\text { Photosynthesis - Yield } \\
\text { Estimation for Crop } \\
\text { (RS-P-YEC) is } \\
\text { proposed. }\end{array}$ & $\begin{array}{l}\text { Remote sensing and meteorological data } \\
\text { is used. The results obtained by this model } \\
\text { are compared with the observation of } \\
\text { meteorological station where R } \text { Reaches }^{2} \\
\text { to 0.817. }\end{array}$ \\
\hline 6. & $\begin{array}{l}\text { Sianqiang REN et al. Filter and Gaussian } \\
\text { Model is used. }\end{array}$ & $\begin{array}{l}\text { Relationship between NDVI calculated } \\
\text { and LAI is established. Main disadvantage } \\
\text { is that crop growth stage indicators are not } \\
\text { discussed. }\end{array}$ \\
\hline
\end{tabular}


Crop Yield Prediction Techniques using Remote Sensing Data

\begin{tabular}{|c|c|c|c|}
\hline 7. & Zongnan Li at al. (2011) & $\begin{array}{l}\text { Crop growth indicators } \\
\text { are used. }\end{array}$ & $\begin{array}{l}\text { Correlation coefficient is calculated. LAI } \\
\text { reveals that SAVI with } \mathrm{L}=0.1 \text { outperforms } \\
\text { in heading stage. }\end{array}$ \\
\hline 8. & Kussul N. et al. (2012) & $\begin{array}{l}\text { MLP, SVM and decision } \\
\text { tree. }\end{array}$ & $\begin{array}{l}\text { The MLP classifier performs the better } \\
\text { result. }\end{array}$ \\
\hline 9. & $\begin{array}{l}\text { Boonyasith K. et al. } \\
\text { (2013) }\end{array}$ & $\begin{array}{l}\text { Progressive Iteration } \\
\text { Method (PIA) is used. }\end{array}$ & $\begin{array}{l}\text { PIA technique perform better than S-G } \\
\text { Filter methods to reduce the noise present } \\
\text { in data set. }\end{array}$ \\
\hline 10 & Kuwata K. et al. (2015) & $\begin{array}{l}\text { Machine learning with } \\
\text { SVR. }\end{array}$ & $\begin{array}{l}\text { Correlation coefficient and RMSE is } \\
\text { calculated. Highest accuracy is achieved } \\
\text { by deep learning with two inner product } \\
\text { layer. }\end{array}$ \\
\hline 11. & Pantazi X.E. et al. (2016) & $\begin{array}{l}\text { CP-ANN, XY-fused } \\
\text { Networks and SKN is } \\
\text { used. }\end{array}$ & $\begin{array}{l}\text { The experiments concluded that SKN } \\
\text { performed better than other two models. }\end{array}$ \\
\hline 12. & Kussul N. et al. (2016) & $\begin{array}{l}\text { Parcel based crop } \\
\text { classification. }\end{array}$ & $\begin{array}{l}\text { Pixel based classification using the parcel } \\
\text { boundaries give the best performance for } \\
\text { crop yield prediction. }\end{array}$ \\
\hline 13. & $\begin{array}{l}\text { Leisa J. Armstrong et al. } \\
\text { (2016) }\end{array}$ & $\begin{array}{l}\text { J48, LADTree, IBk and } \\
\text { LWL classifiers are } \\
\text { used. }\end{array}$ & $\begin{array}{l}\text { MAE, RMSE, RAE and RRSE are } \\
\text { calculated and observed that J48 have } \\
\text { higher accuracy and LWL performed with } \\
\text { low accuracy. }\end{array}$ \\
\hline 14. & $\begin{array}{l}\text { Niketa Gandhi at al. } \\
\text { (2016) }\end{array}$ & $\begin{array}{l}\text { Decision support system } \\
\text { is proposed. }\end{array}$ & $\begin{array}{l}\text { Three categories of output i.e. low yield } \\
\text { from } 0.15 \text { to } 0.60 \text { t/ha, moderate yield } \\
\text { range is from } 0.61 \text { to } 1.10 \text { t/ha and high } \\
\text { yield range is from } 1.11 \text { to } 3.16 \mathrm{t} / \mathrm{ha} \text { is } \\
\text { identified. }\end{array}$ \\
\hline 15. & $\begin{array}{l}\text { Leisa J. Armstrong et al. } \\
\text { (2016) }\end{array}$ & $\begin{array}{l}\text { ANN with multilayer } \\
\text { perceptron technique. }\end{array}$ & $\begin{array}{l}\text { Specificity, sensitivity and accuracy is } \\
\text { calculated. }\end{array}$ \\
\hline 16. & Pritam Bose et al. (2016) & $\begin{array}{l}\text { Spiking Neural Network } \\
\text { computational model. }\end{array}$ & $\begin{array}{l}\text { RMSE, RE, MAE and MBE calculated } \\
\text { with WEKA software. The result accuracy } \\
\text { is } 95.64 \% \text { and average error is } 0.236 \text { t/ha. }\end{array}$ \\
\hline 17 & Kussul N. et al. (2017) & $\begin{array}{l}\text { Multilevel Deep } \\
\text { learning approach. }\end{array}$ & $\begin{array}{l}\text { Classification of different types of crops is } \\
\text { done by using multitemporal multisource } \\
\text { satellite images. }\end{array}$ \\
\hline 18 & You. J. et al. (2017) & $\begin{array}{l}\text { Dimensionality } \\
\text { reduction technique. }\end{array}$ & $\begin{array}{l}\text { LSTM and CNN outperformed when } \\
\text { added with Gaussian Product and RMSE } \\
\text { is reduced by } 30 \% \text { when compared with } \\
\text { the ridge regression method. }\end{array}$ \\
\hline 19. & $\begin{array}{l}\text { Md. Akter Hossain et al. } \\
\text { (2017) }\end{array}$ & $\begin{array}{l}\text { Weather-based } \\
\text { prediction system } \\
\text { approach is used. }\end{array}$ & $\begin{array}{l}\text { Accuracy of 93.64\%, sensitivity of } \\
89.36 \% \text { and specificity of } 91.72 \% \text { is } \\
\text { achieved. }\end{array}$ \\
\hline 20. & $\begin{array}{l}\text { A.K. Mariappan et al. } \\
\text { (2017) }\end{array}$ & $\begin{array}{l}\text { Crop simulation } \\
\text { paradigm. }\end{array}$ & $\begin{array}{l}\text { The paradigm can be used to train a } \\
\text { system. }\end{array}$ \\
\hline 21. & Ji. S. et al. (2018) & 3D CNN model & $\begin{array}{l}\text { Results of 3D CNN models are compared } \\
\text { with 2D CNN and shallow methods and } \\
\text { concluded that 3D CNN achieved a near- } \\
\text { perfect crop classification accuracy. }\end{array}$ \\
\hline 22. & $\begin{array}{l}\text { Hossein Aghighi et al. } \\
\text { (2018) }\end{array}$ & $\begin{array}{l}\text { BRT, RFR, SVR and } \\
\text { GPR are used. }\end{array}$ & $\begin{array}{l}\text { Machine learning techniques perform } \\
\text { better than conventional regression } \\
\text { techniques. }\end{array}$ \\
\hline
\end{tabular}

\section{CONCLUSION}

Many models and techniques proposed by the researchers have been presented for yield prediction of crops before the actual harvesting. In the early stage the field survey was conducted and by using the various factors like soil, climate, fertilizer, irrigation etc. and available past statistics the yield of the crops was forecasted. Statistical models used for forecasting yield are less parameter-intensive and simple in their usage, but the information provided by these models are limited and provide outside the range of values for which the model is parameterized. After the emergence of remote sensing the yield of the crop was predicted with the help of satellite imagery and using regression equations which were also questionable. Further, machine learning techniques come into force; these were applied with the satellite imagery and other physiochemical parameters of soil. 


\section{REFERENCES}

1. Serele, C.Z., Gwyn, Q.H J., Boisvert, J.B., Pattey, E., McLaughlin, N., Daoust, G., "Corn Yield Prediction with Artificial Neural Network trained using Airborne Remote Sensing and Topographic Data", IEEE International Geoscience and Remote Sensing Symposium, vol. 1, pp. 384-386, 2000.

2. Jingfeng, H., Shuchuan, T., Abou-Ismail, O., Renchao, W., "Integration of remote sensing data and simulation model to estimate rice yield", IEEE International Conference on Info-Tech and Info-Net, vol. 1, pp. 101-107, 2001.

3. Patel, N.R., Bhattacharjee, B., Mohammed, A.J., Tanupriya, B., Saha, S. K., "Remote sensing of regional yield assessment of wheat in Haryana, India”, International Journal of Remote Sensing, vol. 27, no. 19, pp. 4071-4090, 2006.

4. Jaikla, R., Auephanwiriyakul, S., Jintrawet, A., "Rice Yield Prediction using a Support Vector Regression method", IEEE proceedings of Electrical Engineering/Electronics, Computer, Telecommunications and Information Technology, vol. 1, pp. 29-32, 2008.

5. Peijuan, W., Jiahua, Z., Donghui, X., Yuyu, Z., Rui, S., "Yield estimation of winter wheat in north china plain using RS-P-YEC model", IEEE International Geoscience and Remote Sensing Symposium, vol. 4, pp. 378-381, 2009.

6. Ren, J., Chen, Z., Yang, X., Liu, X., Zhou, Q., "Regional yield prediction of winter wheat based on retrieval of leaf area index by remote sensing technology", IEEE International Geoscience and Remote Sensing Symposium, vol. 4, pp. 374-377, 2009.

7. Li, Z., Chen, Z., "Remote sensing indicators for crop growth monitoring at different scales", IEEE International Geoscience and Remote Sensing Symposium, pp. 4062-4065, 2011.

8. Khobkhun, B., Prayote, A., Rakwatin, P., Dejdumrong, N., "Rice phenology monitoring using PIA time series MODIS imagery", IEEE 10th International Conference Computer Graphics, Imaging and Visualization, pp. 84-87, 2013.

9. Manjula, A., Narsimha, G., "XCYPF: A Flexible and Extensible Framework for Agricultural Crop Yield Prediction”, IEEE Sponsored 9th International Conference on Intelligent Systems and Control, pp. 15, 2015.

10. Gandhi, N., Armstrong, L.J., "Rice Crop Yield Forecasting of Tropical Wet and Dry Climatic Zone of India Using Data Mining Techniques", IEEE International Conference on Advances in Computer Applications, pp. 357-363, 2016.

11. Gandhi, N., Armstrong, L.J., Petkar, O., "Proposed Decision Support System (DSS) for Indian Rice Crop Yield Prediction", IEEE International Conference on Technological Innovations in ICT For Agriculture and Rural Development, pp. 13-18, 2016.

12. Gandhi, N., Armstrong, L.J., Petkar, O., "Rice Crop Yield Prediction Using Artificial Neural Networks", IEEE International Conference on Technological Innovations in ICT For Agriculture and Rural Development, pp. 105-110, 2016.

13. Bose, P., Kasabov, N.K., "Spiking Neural Networks for Crop Yield Estimation Based on Spatiotemporal Analysis of Image Time Series", IEEE transactions on geoscience and remote sensing, vol. 54, no. 11, pp. 6563-6573, 2016.

14. Stas, M., Orshovn, J.V., Dong, Q., Heremans, S., Zhang, B., "A Comparison of machine learning algorithm for regional wheat yield prediction using NDVI time series of SOPT-VGT", IEEE International Conference Agro-Geoinformatics, pp. 1-5, 2016.

15. Fernandez, Y.M., Soria, R.J., "Maize crop yield estimation with remote sensing and empirical models", IEEE International Geoscience and Remote Sensing Symposium, pp. 3035-3038, 2017.

16. Wakamori, K., Ichikawa, D., Oguri, N., "Estimation of rice growth status protein content and yield prediction using multi-satellite data", IEEE International Geoscience and Remote Sensing Symposium, pp. 5089-5092, 2017.

17. Hossain, M.A., Uddin, M.N., Hossain, M.A., Jang, Y.M., "Predicting rice yield for Bangladesh by exploiting weather conditions", IEEE International Conference on ICT Convergence, pp. 589-594, 2017.

18. Mariappan, A.K., Das, J.A.B., "A paradigm for rice yield prediction in Tamilnadu", IEEE International conference on Technological innovations in ICT for agriculture and rural development", pp. 18-21, 2017.

19. Siddique, T., Barua, D., Ferdous, Z., Chakrabarty, A., "Automated Farming Prediction”, IEEE Intelligent Systems Conference, pp. 757 763, 2017.

20. Aghighi, H., Azadbakht, M., Ashourloo, D., Shahrabi, H.S., Radiom, S., "Machine Learning Regression Techniques for the Silage Maize Yield Prediction Using Time-Series Images of Landsat 8 OLI", IEEE Journal of Selected Topics in Applied Earth Observations and Remote Sensing", Early access, pp. 1-15, 2018.
21. Kussul, N., Lavreniuk, M., Skakun, S., and Shelestov, A., "Deep learning classification of land cover and crop types using remote sensing data," IEEE Geoscience and Remote Sensing Letters, vol. 14 no. 5, pp. 778-782, 2017.

22. Pantazi, X.E., Moshou, D., Alexandridis, T., Whetton, R.L., Mouazen, A.M., "Wheat yield prediction using machine learning and advanced sensing techniques" Elsevier Computer and electronics in agriculture, pp. 57-65, 2016.

23. J. You, X. Li, M. Low, D. Lobell, and S. Ermon, "Deep Gaussian Process for Crop Yield Prediction Based on Remote Sensing Data." AAAI conference on Artificial Intelligence, pp. 4559-4566, 2017.

24. N. Kussul, G. Lemoine, F. J. Gallego, S. V. Skakun, M. Lavreniuk, and A. Y. Shelestov, "Parcel-based crop classification in Ukraine using Landsat-8 data and Sentinel-1A data," IEEE J. Sel. Topics Appl. Earth Observ. Remote Sens., vol. 9, no. 6, pp. 2500-2508, Jan. 2016.

25. B. Basso, D. Cammarano, and E. Carfagna, "Review of crop yield forecasting methods and early warning systems," in Proceedings of the First Meeting of the Scientific Advisory Committee of the Global Strategy to Improve Agricultural and Rural Statistics, FAO Headquarters, Rome, Italy, pp. 18-19, 2013.

26. K. Kuwata and R. Shibasaki, "Estimating crop yields with deep learning and remotely sensed data," in Geoscience and Remote Sensing Symposium (IGARSS), 2015 IEEE International. IEEE, pp. 858-861, 2015.

27. S. Ji, C. Zhang, A. Xu, Y. Shi, and Y. Duan, "3D convolutional neural networks for crop classification with multi-temporal remote sensing images", Remote Sensing, vol. 10, no. 1, pp. 75-92, 2018.

28. N. Kussul, S. Skakun, A. Shelestov, O. Kravchenko, J.F. Gallego, and O. Kussul, "Crop area estimation in Ukraine using satellite data within the MARS project," in: IGARSS 2012, 22-27 July 2012, Munich, Germany, pp. 3756-3759.

29. Kumar V., Garg, M.L., "Deep Learning in predictive analytics: A survey", IEEE International Conference on Emerging Trends in Computing and Communication Technologies (ICETCCT), 2017.

30. Ji, S. Xu, W. Yang, M. Yu, K., "3D convolutional neural networks for human action recognition", IEEE Transaction on pattern analysis and machine intelligence, Vol.35, pp 221-231, 2013.

31. Tran, D., Bourdev L., Fergus R., Torresani L., Paluri M.., "Learning spatiotemporal features with 3D convolutional networks", In Proceedings of the 2015 IEEE International Conference on Computer Vision, pp. 4489-4497, 2015.

32. Doraiswamy, P.C., J.L. Hatfield, T.J. Jackson, et al. "Crop condition and yield simulations using landsat and MODIS". Remote Sensing of Environment, 92: 548-559 (2004). https://semiengineering.com/deep-learning-spreads/ 